\title{
TWO SEQUENCES OF OPERATOR MONOTONE FUNCTIONS UNDER STRICTLY CHAOTIC ORDER
}

\author{
JiANFEI JiAng, HONGLIANG ZUO AND MEIYAN WANG
}

Abstract. Based on the well-known operator monotone function $\log t$ the chaotic order was defined by $A \gg B$, e.g. $\log A \geqslant \log B$, and thereby the operator monotonicity of functions under strictly chaotic order has been introduced. However, until now the revealed operator functions with such property have been less than those functions under usual order. In this study, we investigate two sequences of operator monotone functions under strictly chaotic order, following the trace of Professor T. Furuta, S. Izumino and so on. However, the method is different from that of the relative results on

$$
f_{0}(t)=\frac{t-1}{\log t}, f_{p}(t)=\frac{t-p f_{p-1}(t)}{\log t}, p=1,2, \cdots
$$

due to S. Izumino and N. Nakamura.

Mathematics subject classification (2010): 47A30, 47A63.

Keywords and phrases: operator monotone function, positive operator, strictly chaotic order.

\section{REFERENCES}

[1] S. IzUmino AND N. NAKAmURA, Operator monotone functions induced from Löwner-Heinz inequality and strictly chaoic order, Math. Inequal. Appl., 7 (2004), 103-112.

[2] K. LÖWnER, Über monotone Matrixfunktionen, Math. Ann., 38 (1934), 177-216.

[3] M. K. Kwong, Some results on matrix monotone functions, Linear Algebra Appl., 118 (1989), 129_ 153.

[4] T. FURUTA, An operator monotone function $\frac{t \log t-t+1}{\log ^{2} t}$ and strictly chaotic order, Linear Algebra Appl., 341 (2002), 101-109.

[5] J. F. JIANG AND L. ZHANG, Two sequence of operator monotone functions, 14th conferece of the inter. Linear Algebra Soc. (2006), 103-106. 